Proc. Indian Acad. Sci. (Chem. Sci.), Vol. 108, No. 5, October 1996, pp. 505-510.

(c) Printed in India.

\title{
Synthesis and catalytic properties of cobalt- and molybdenum-containing mesoporous MCM-41 molecular sieves
}

\author{
S AYYAPPAN*1 and N ULAGAPPAN ${ }^{2}$ \\ ${ }^{1}$ Materials Research Centre, Indian Institute of Science, Bangalore 560012, \\ India \\ ${ }^{2}$ Jawaharlal Nehru Centre for Advanced Scientific Research, Jakkur, Bangalore \\ 560064 , India
}

MS received 19 September 1996

\begin{abstract}
Mesoporous MCM-41 type silicas containing molybdenum and cobalt have been prepared with pore sizes in the range $30-38 \AA$ and $54-59 \AA$. Catalytic properties of these materials have been examined with respect to the oxidation of cyclooctene and aniline.
\end{abstract}

Keywords. Mesoporous silica; $\mathrm{MCM}-41 ; \mathrm{Co}-\mathrm{SiO}_{2} ; \mathrm{Mo}-\mathrm{SiO}_{2} ;$ molecular sieves.

Mesoporous silica of MCM-41 type was reported sometime ago by Beck et al (1992). Since then severai derivatives of MCM-41 containing Ti, V, Mn and Fe have been prepared and tested for their catalytic activity (Reddy et al 1994; Schmidt et al 1994; Tanev et al 1994; Yuan et al 1995; Zhao and Goldfarb 1995). Many of these mesoporous materials show redox catalytic properties. Thus, chromium-containing MCM-41 type silicates with redox properties have just been reported (Ulagappan and Rao 1966). In this communication, we report the synthesis of MCM-41 type silicas containing Mo and $\mathrm{Co}$ and their catalytic properties.

In order to synthesize Mo-containing mesoporous silica, a gel of composition $\mathrm{SiO}_{2}: 0 \cdot 15 \mathrm{Na}_{2} \mathrm{O}: 0.25 \mathrm{TDTAB}: 0 \cdot 02 \mathrm{MoO}_{3}: 60 \mathrm{H}_{2} \mathrm{O}$ was prepared from tetraethylorthosilicate (TEOS), $\mathrm{NaOH}$, tetradecyltrimethylammonium bromide (TDTAB), sodium molybdate and distilled water. In a typical synthesis, $\mathrm{NaOH}(12.49 \mathrm{mmol})$ solution containing TEOS ( $44.7 \mathrm{mmol})$ was added to the TDTAB $(10.4 \mathrm{mmol})$ solution under stirring. The sodium molybdate $(2.08 \mathrm{mmol})$ solution was added to the above mixture and the whole mixture stirred for $30-45 \mathrm{~min}$. The gel so obtained was taken in an air-tight polypropylene bottle and heated at $363 \mathrm{~K}$ for a period of $24 \mathrm{~h}$ in a hot-air oven. The solid obtained was filtered, washed several times with distilled water and dried at $373 \mathrm{~K}$ for $6 \mathrm{~h}$.

Cobalt-substituted mesoporous silica was prepared by starting with a gel having the composition $\mathrm{SiO}_{2}: 0 \cdot 25 \mathrm{TDTAB}: 0 \cdot 02 \mathrm{CoO}: 60 \mathrm{H}_{2} \mathrm{O}$. The source of Co was cobalt acetate. In a typical synthesis, $\mathrm{NaOH}(11.6 \mathrm{mmol})$ solution containing TEOS $(23 \mathrm{mmol})$ was added to the TDTAB $(6.27 \mathrm{mmol})$ solution under stirring. The cobalt acetate $(4.63 \mathrm{mmol})$ solution was added to the above mixture and the mixture stirred for $30-45 \mathrm{~min}$. The gel obtained was taken in an air-tight polypropylene bottle and heated at $363 \mathrm{~K}$ for a period of $24 \mathrm{~h}$ in a hot air oven. The product was then filtered, washed several times with distilled water and dried at $373 \mathrm{~K}$ for $6 \mathrm{~h}$. By the procedures

\footnotetext{
* For correspondence
} 
described above, we could obtain hexagonal mesoporous silicas containing Mo or Co with $d_{100}$ values of around $30-38 \AA$.

We also prepared Mo and Co containing mesoporous silica phases with larger pore sizes. We accomplished this by adding tetradecane $(0.25 \mathrm{~mol})$ as the solubilizing agent along with the surfactant (TDTAB) during the preparation of the gel. The actual quantities of tetradecane added in the case of Mo- and Co-containing silicas of the compositions described earlier were $5.79 \mathrm{mmol}$ and $1.15 \mathrm{mmol}$ respectively.

Powder X-ray diffraction (XRD) patterns were recorded using a Rich-Seifert instrument (Model XRD 3000 TT). Transmission electron microscopy (TEM) was carried out using a JEOL JEM3010 instrument operated at $300 \mathrm{kV}$. Thermogravimetric analysis was carried out with a Polymer instrument (Model STA 1500). EDAX (Leica model s 440i) analysis was done on these samples to estimate the composition of Mo and Co. Infrared spectra were recorded using a Perkin-Elmer (Model 580) spectrometer. Diffuse reflectance spectra were recorded with a Unicam (Model SP8100) spectrometer. Surface areas were. measured by the BET method employing Micromeritics rapid surface area analyser, 2200.

In figure 1, we give the XRD patterns of the Mo-containing mesoporous silicas prepared by us. The diffraction profile of the as-synthesized (AS) sample (figure 1a) gives a $d_{100}$ value of $37 \cdot 12 \AA$. Thermogravimetry indicates complete loss of the TDTAB

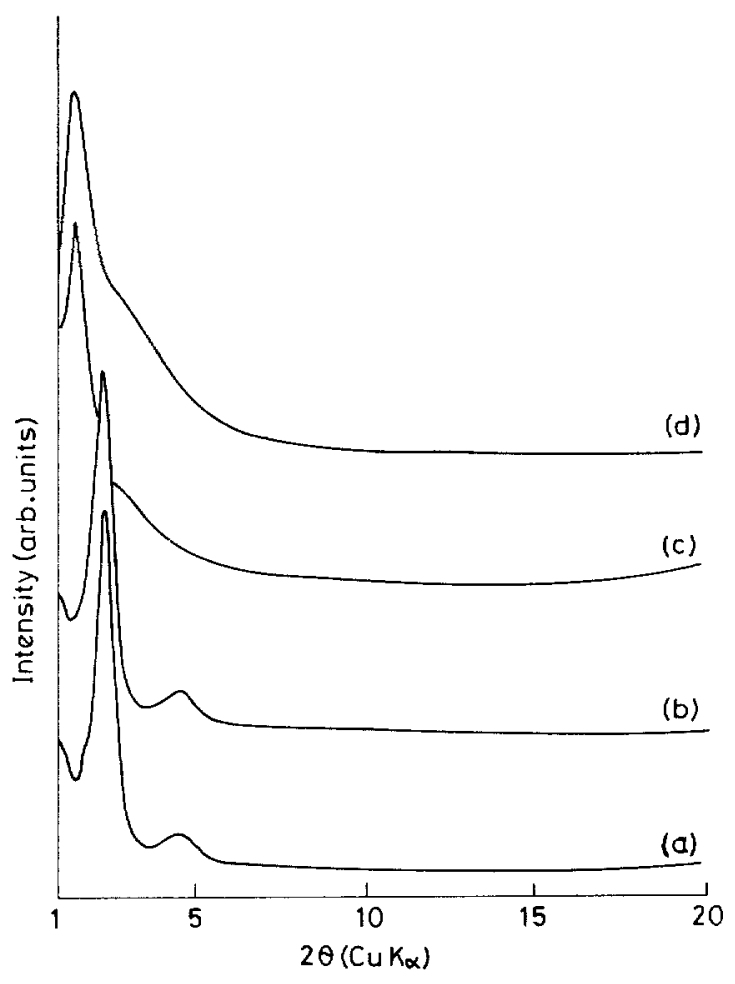

Figure 1. XRD profile of (a) as synthesized Mo containing mesoporous silica with a $d_{100}$ of $37.12 \AA$, (b) ethanol extracted product from (a) with a $d_{100}$ of $37.54 \AA$, (c) as synthesized Mo-containing mesoporous silica with a $d_{100}$ of $56.59 \AA$ and (d) ethanol extracted product from (c) with $d_{100}$ of $56.58 \AA$. 


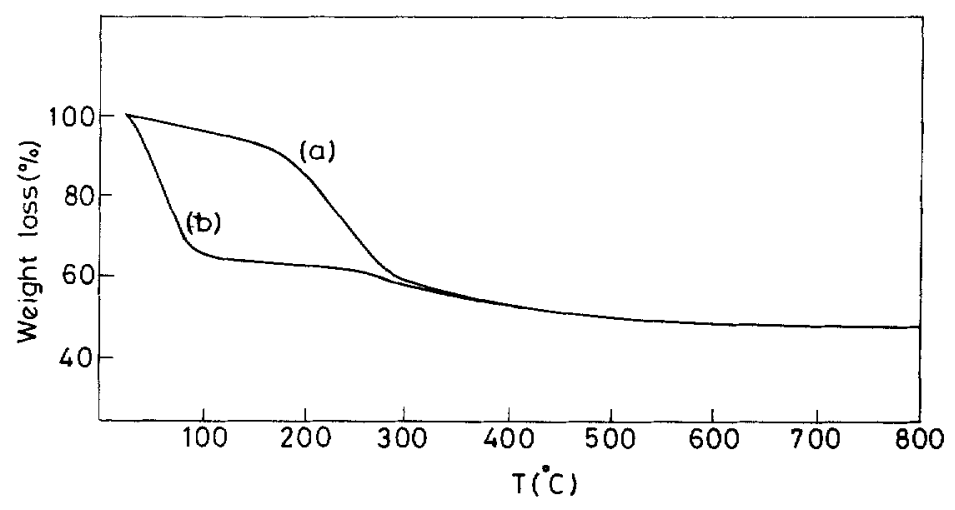

Figure 2. Thermogravimetric curves of (a) Mo-containing mesoporous silica with a $d_{100}$ of $37 \cdot 12 \AA$ and (b) the ethanol extracted product from (a).

template around $673 \mathrm{~K}$ (figure 2). Calcination of the as-synthesized at $673 \mathrm{~K}$ however destroys the structure, as revealed by X-ray diffraction. We therefore removed the template by ethanol extraction. The complete removal of the template was confirmed by the absence of $\mathrm{C}-\mathrm{H}$ stretching vibrations in the infrared spectrum of the product after the extraction and also from the absence of weightloss over the temperature range where the template is normally removed (figure 2 ). In figure $1 \mathrm{~b}$, we have shown the XRD pattern of the ethanol-extracted (EE) product with a $d_{100}$ value of $37.54 \AA$ indicating the retention of the mesoporous structure. By adding tetradecane as the solubilizing agent along with surfactant, we could get Mo-containing silica with an enhanced $d_{100}$ value of $56.59 \AA$, as can be seen from figure 1c. The XRD pattern of the corresponding EE product in figure $1 \mathrm{~d}$ shows a $d_{100}$ value of $56.58 \AA$. Thermogravimetry reveals that $0.2 \mathrm{~mol}$ of TDTAB is incorporated in the $\mathrm{Mo}-\mathrm{SiO}_{2}$ samples prepared. The presence of Mo in the samples was established by EDAX analysis, which gave the Mo content to be $2.0(\mathrm{~mol}) \%$, but we cannot be entirely certain that Mo substitutes $\mathrm{Si}$. The oxidation state of Mo is $6+$ and the extra positive charge in the framework is probably compensated by the bromide ions. While the XRD profiles clearly demonstrate the mesoporous nature of the Mo-silicas prepared by us, we have also employed transmission electron microscopy to establish the hexagonal nature of these phases.

XRD profiles of Co-containing mesoporous silicas are given in figure 3. The assynthesized (AS) sample gives a $d_{100}$ value of $34.33 \AA$ as shown in figure 3a. Thermogravimetry of this sample shows weight loss due to the removal of the template around $723 \mathrm{~K}$ (figure 4). When the as-synthesized sample was calcined at $873 \mathrm{~K}$, we found that the mesostructure remained intact unlike in the case of mesoporous Mo-silica. The complete removal of the template was confirmed by the absence of the $\mathrm{C}-\mathrm{H}$ stretching vibrations in the infrared spectrum. In figure $3 \mathrm{~b}$ we give the XRD profile of the calcined ( $873 \mathrm{~K}$ ) Co-silica material with a $d_{100}$ value of $29 \cdot 47 \AA$.

Addition of tetradecane to the Co-containing silica gel increases the pore size of the mesoporous phase as can be seen from the XRD profile (figure 3c) showing a $d_{100}$ of $59.64 \AA$. The XRD profile of the product calcined at $873 \mathrm{~K}$ in air gives a $d_{100}$ value of $53.82 \AA$. The template content of the mesoporous Co-silica as determined by thermogravimetry is $0.2 \mathrm{~mol}$. EDAX analysis gives the cobalt content as $3.0(\mathrm{~mol}) \%$. The hexagonal mesoporous nature of the Co-containing silicas was also confirmed by 


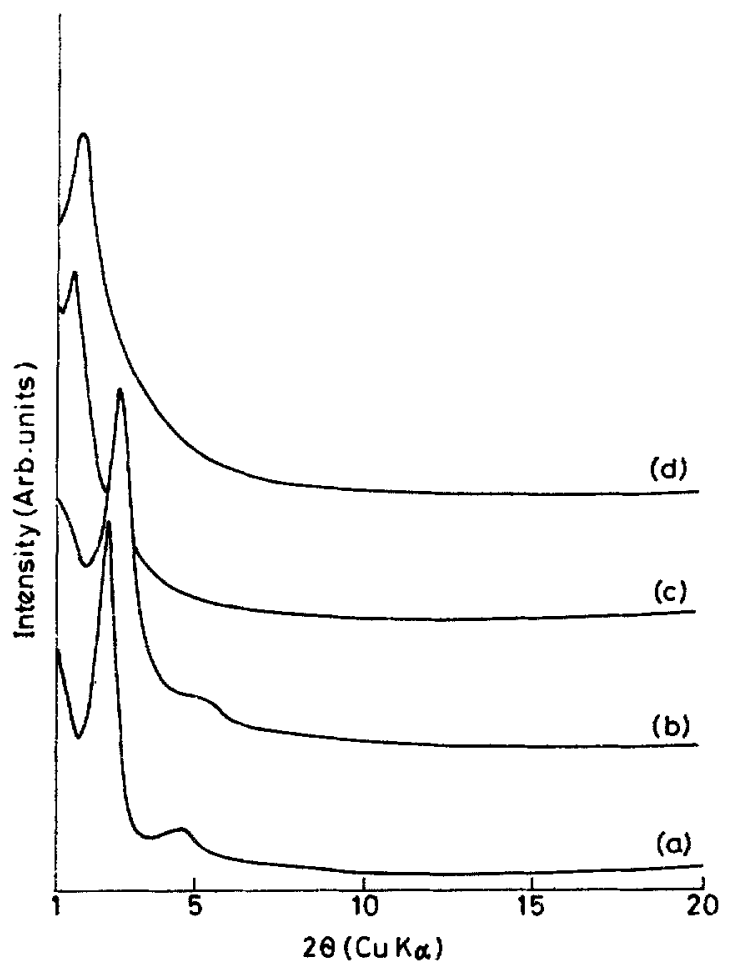

Figure 3. XRD profiles of (a) as-synthesized Co-containing mesoporous silica with a $d_{100}$ of $34 \cdot 33 \AA$, (b) sample (a) after calcination showing a $d_{100}$ of $29 \cdot 47 \AA$. (c) sc-sunthesized Co-containing mesoporous silica with a $d_{100}$ of $59.64 \AA$ and (d) sample (c) after caicination showing a $d_{100}$ of $53.82 \AA$.

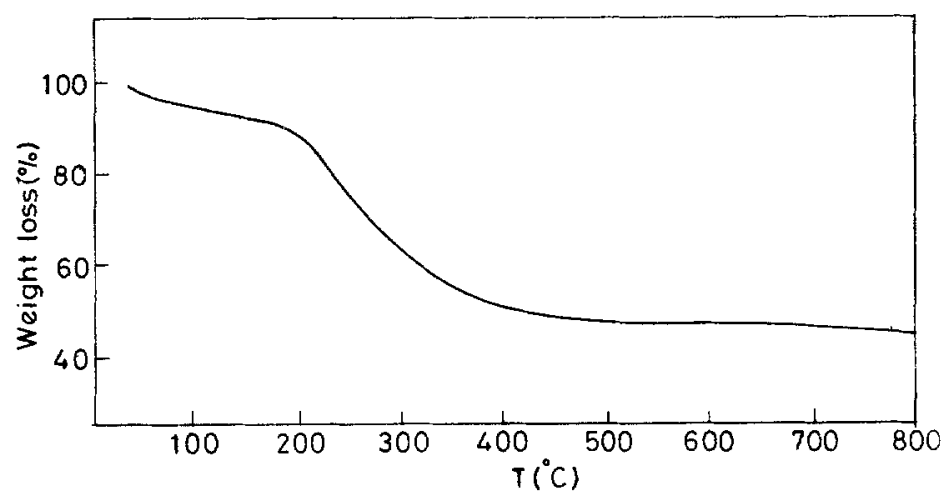

Figure 4. Thermogravimetric curve of Co-containing mesoporous silica with a $d_{100}$ of $34 \cdot 33 \AA$.

TEM. Diffuse reflectance spectra (figure 5) of as-synthesized Co-silica samples (light pink in colour) show a broad band around $550 \mathrm{~nm}$, but on calcination at $873 \mathrm{~K}$ the product turns blue in colour and shows peaks around 520,585 and $650 \mathrm{~nm}$ confirming 


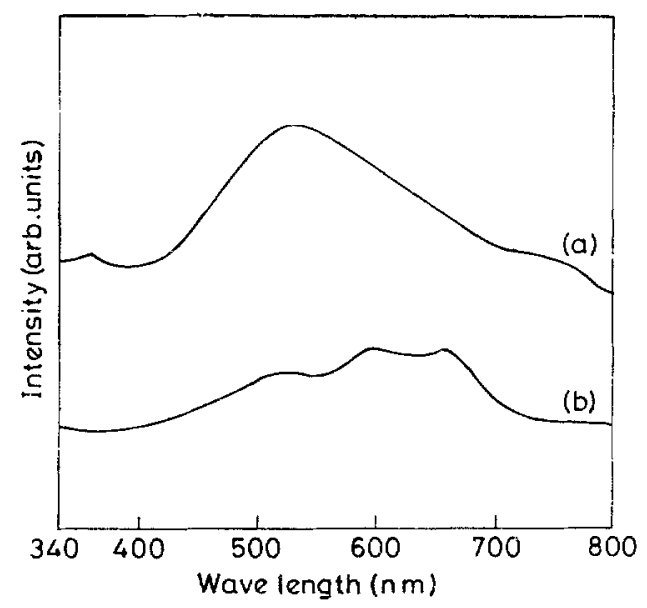

Figure 5. Diffuse reflectance spectra of (a) as-synthesized Co-containing mesoporous silica and (b) the calcined sample.

Table 1. Properties of Mo- and Co-containing mesoporous silicas.

\begin{tabular}{lccc}
\hline Compound $^{a}$ & $d_{100}(\AA)$ & $a_{0}(\AA)$ & $\begin{array}{c}\text { Surface area } \\
\left(\mathrm{mg}^{2} \mathrm{~g}^{-1}\right)\end{array}$ \\
\hline $\mathrm{Mo}-\mathrm{SiO}_{2}$ (AS) & 37.12 & 42.86 & - \\
$\mathrm{Mo}-\mathrm{SiO}_{2}$ (EE) & 37.54 & 43.35 & 453 \\
$\mathrm{Mo}-\mathrm{SiO}_{2}$ (AS) & 56.59 & 65.34 & - \\
$\mathrm{Mo}-\mathrm{SiO}_{2}$ (EE) & 56.58 & 65.33 & 1068 \\
$\mathrm{Co}-\mathrm{SiO}_{2}$ (AS) & 34.33 & 39.64 & - \\
$\mathrm{Co}-\mathrm{SiO}_{2}$ (C) & 29.47 & 34.04 & 552 \\
$\mathrm{Co}-\mathrm{SiO}_{2}$ (AS) & 59.64 & 68.87 & - \\
$\mathrm{Co}-\mathrm{SiO}_{2}$ (C) & 53.82 & 62.15 & 801 \\
\hline
\end{tabular}

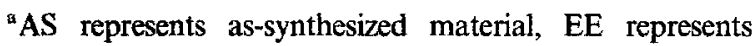
ethanol extracted product and $C$ represents calcined sample.

the presence of $\mathrm{Co}(\mathrm{II})$ at tetrahedral sites. We note that the tetrahedral $\mathrm{Co}$ (II) ions can readily substitute $\mathrm{Si}$ sites in $\mathrm{SiO}_{2}$, thus explaining the thermal stability of the mesoporous Co-silicas, in contrast to that of Mo-silica.

In table 1 , we have listed the $d_{100}$ values of the various mesoporous silicas prepared by us along with their unit-cell parameter $a_{0}$, using the formula $a_{0}=2 d_{100} / \sqrt{3}$. We have also listed the values of the surface area obtained by the BET method for the template-free samples in the same table. As we can see, the surface area is generally large, varying between 453 and $1068 \mathrm{~m}^{2} \mathrm{~g}^{-1}$, clearly establishing the mesoporous nature of the sample.

We have carried out preliminary experiments on the oxidation of cyclooctene and aniline using the various mesoporous $\mathrm{Mo}$ - and $\mathrm{Co}$-silica materials prepared by us. The reactions were carried out at $343 \mathrm{~K}$ for $24 \mathrm{~h}$ in the presence of $\mathrm{H}_{2} \mathrm{O}_{2}\left(\mathrm{H}_{2} \mathrm{O}_{2}\right.$ : reactant 
molar ratio was $1: 3$ ). In the case of Co-silica, $2.0 \%$ of cyclooctene oxide and $4.0 \%$ of the other oxidation products were obtained independent of the pore-size. With Co-silica, aniline gets oxidized to azobenzene, nitrobenzene and other products ( $1 \%$ each), again independent of the pore size. In the case of Mo-silica $\left(d_{100} \approx 37 \AA\right)$, we found greater oxidation of cyclooctene. We obtained $8 \%$ cyclooctene oxide and $15 \%$ of the other oxidized products. With the larger pore size $\left(d_{100} \approx 56 \AA\right), 2 \%$ cyclooctene oxide and $7 \%$ of other products were obtained. With Mo-silica $\left(d_{100} \approx 37 \AA\right)$ the product distribution in the oxidation of aniline was $1 \%$ azobenzene and $7 \%$ nitrobenzene along with $8 \%$ of other products. With the $d_{100} \approx 56 \AA$ sample, $1 \%$ azobenzene, $2 \%$ nitrobenzene and $7 \%$ of other products were obtained. It is possible to incorporate $\mathrm{Mo}(\mathrm{VI})$ and $\mathrm{Co}(\mathrm{II})$ in mesoporous silica of the MCM-41 type. The pore size is $30-38 \AA$ when we use tetradecyltrimethylammonium bromide as the surfactant. The pore size can be expanded to $54-59 \AA$ by using tetradecane as the solubilizing agent. The surface areas of the $\mathrm{Mo}$ - and $\mathrm{Co}$-containing mesoporous silicas prepared by us are in the range $453-1068 \mathrm{~m}^{2} \mathrm{~g}^{-1}$. Mesoporous $\mathrm{Mo}-\mathrm{SiO}_{2}$ and $\mathrm{Co}-\mathrm{SiO}_{2}$ exhibit oxidizing catalytic properties.

\section{References}

Beck J S, Vartuli J C, Roth W J, Leonowicz M E, Kresge C J, Schmidt K D, Chu C T W, Olson D H, Sheppard E W, McCullen S B, Higgins J B and Sclenter J L 1992 J. Am. Chem. Soc. 11410834

Reddy K M, Moudrakovski I and Sayari A 1994 J. Chem. Soc., Chem. Commun. 1059

Schmidt R, Akporiaye D, Stocker M and Ellestad O H 1994 J. Chem. Soc., Chem. Commun. 1493

Tanev P T, Chibwe M and Pinnavaia T J 1994 Nature (London) 368321

Ulagappan N and Rao C N R 1996, J. Chem. Soc., Chem. Commun. 1047

Yuan Z Y, Liu S Q, Chen T H, Wang J Z and Li H X 1995 J. Chem. Soc., Chem. Commun. 973

Zhao D and Goldfarb D 1995 J. Chem. Soc., Chem. Commun. 875 